\title{
Meta-Interpretation: Fifteen Years of Research with the Management Report
}

\author{
Uajará Pessoa Araújo \\ Centro Federal de Educação Tecnológica de Minas Gerais, Departamento de Ciências Sociais Aplicadas, Programa de Pós-Graduação em Administração, Belo Horizonte, MG, Brazil
}

Mozar José de Brito

Universidade Federal de Lavras, Departamento de Administração e Economia, Lavras, MG, Brazil

Lívia Maria de Pádua Ribeiro

Centro Federal de Educação Tecnológica de Minas Gerais, Departamento de Ciências Sociais Aplicadas, Programa de Pós-Graduação em Administração, Belo Horizonte, MG, Brazil

\begin{abstract}
This paper deals with Brazilian empirical research published in journals between 2000 and mid-2015 that used, as a source of data, the Management Reports (MRs) released by publicly-traded companies together with their financial statements. MRs differ from each other, both in form as well as in substance, and due to this as well as to their other characteristics, they prove attractive for academic studies interested in official company discourse, more so because they involve documents that are public and retrievable over time, covering a substantial range of typically larger companies from different economic sectors. Driven by these characteristics, the goal of this study was to understand the way the academic world understands and uses the MR. The paper favored an interpretivist viewpoint, but used the triangulation allowed by the use of qualitative (content analysis) and quantitative (statistical, sociometric, and bibliometric analyses) methods. It was concluded that, for the core group of experts who dealt with the document, the MR is biased, incomplete, questionable, unclear, laborious, uncertain, but also useful - in the absence of another -, comprehensive, available, and retrievable over time. And it lends itself to the interest of company directors by increasing their value and at the same time legitimizing their companies; incorporating into discourse the use of contemporary management practices, consistent with the expectations of stakeholders. Finally, it suggests the possibility, unexplored in the articles analyzed, of employing the MR to study the dynamics of the institutionalization of administrative practices among companies in the country.
\end{abstract}

Keywords: legitimization, institutionalization, meta-interpretation, management report. 


\section{INTRODUCTION}

The Management Report (MR) is an obligatory document for publicly-traded companies, which must be released at the close of the financial year together with Standardized Financial Statements (SFS) and Explanatory Notes (EN). It complements these and contemplates the main administrative facts, including, optionally and among other things, a description of the businesses and products, an analysis of relevant exogenous factors regarding company performance, the state of research and development projects, questions relating to protecting the environment, and the application of administrative streamlining programs (Brasil, 1976; Brazilian Securities and Exchange Commission [Comissão de Valores Mobiliários - CVM], 1987).

It should be noted that the independent auditing of publicly-traded companies (obligatory auditing imposed by $\$ 3$ of Article 177 of Act 6,404 of 1976 and conducted under the responsibility of auditors who, as well as being external to the organization, must also be registered at the CVM) does not analyze nor evaluate the content of MRs (Kos, Espejo, \& Raifur, 2014), as can be observed in the Independent Auditing of Financial Statements Norm NBC T 11, in contrast with the thorough examination of content required of other parts of financial statements. Because of this, and due to the narrative and flexible character of the MR, this document can make use of the creativity of an entity's Administration, which should redact it using simple language in order to make it accessible for the greatest number of readers possible, to the point of potentially transforming it into a powerful element for communicating useful and detailed information, allowing for understanding of the company, its objectives and policies (Brasil, 1976; CVM, 1987) and contributing to its legitimacy, as understood in Lindblom (1994) and Suchman (1995).

As a result, MRs differ from each other, both in form and in substance, thus proving attractive, because of this as well as their other characteristics, for academic studies interested in the official discourse of companies, primarily due to the documents being public and retrievable over time, covering a substantial range of typically larger companies from different economic sectors.

Hypothetically, in the most basic way, these studies could focus on the MR issuer (referred to here as the Administrator) and the factors conditioning its production. In this case, the concern would either be the effect of the Administrator's personal characteristics and the incidence of the agency phenomenon, or they would address the different factors influencing the Administrator, such as size and shareholder composition; the results for the financial year; and also the consequences of economic dynamics. The coding used (semantic choices, linguistic forms, preferences, and its structuring) and the content of the message itself - even the unwritten - are other obvious concerns. Moreover, and in theory, the papers may opt to discuss the relative efficiency of the MR compared with alternative means and channels of communication (Social Report, Environmental Report, company websites).

Finally, investigations focusing on those receiving the message are also important. These are numerous, including those listed by the CVM (1987) and prioritizing: shareholders, creditors, suppliers, and clients; as well as competitors, employees, unions, regulatory bodies, trade associations, investment analysts, and economic journalists - measuring how well the specific needs of each category are met or the impact of the MRs on the decisions of one or more groups; and consequently, on the equity market.

It was not difficult to find 95 empirical investigations with varied theoretical frameworks and objectives, which used the MR as a source of data from 2000 onwards, each one borrowing from the document in its own way. Thus, respecting the individuality of the investigations, it was envisaged that it would be feasible to extract a representation of the significance of the MR from the papers, exploring regularities and singularities, the institutional environment, and primarily, the researchers and their methodological options - at the same time responsible for the papers and almost exclusive "consumers" of the products created. Therefore, the meta-interpretation referred to in this article proposes to answer the following question: what does the Management Report mean to Brazilian researchers?

The relevance of the study would lie, answering the study question, in discovering and appreciating other possible meanings for the MR, indicating the potentials of analyzing it, which have not yet been explored satisfactorily and therefore opening up other opportunities for understanding management and accounting practices in the country.

It is important to state straight away that a literature review regarding the MR was not proposed nor carried out, avoiding the risk of the product resulting in, as indicated by Wood (2000), pseudo synthesis, or rather, nothing more than a commentated bibliography, a "tour" through what might appear important. The intention of offering a meta-interpretation - understood here as an understanding that goes beyond content and the omissions from the articles taken individually, making progress in the integration and in the metadata, such as authorship, journal, and year of publication, and other indications of collective production in the Brazilian scientific environment - in the direction suggested by Weed (2005), which points to the urgency of this type of investigation in psychology and medicine, while there is relatively little meta-interpretation in social sciences, due to a lack of expertise in accumulating and reusing papers already published, primarily those of an interpretative nature. Nevertheless, Weed (2005) indicates diffe- 
rent methodological options available to those interested; among which include: meta-analysis, meta-ethnography, cross comparison of cases, secondary analysis of primary data, and phenomenological-interpretative analysis. Whichever the choice, the meta-interpretation needs to produce a new understanding, unlike merely compiling findings from original studies - a commitment of this study and which serves as a test of its relevance.

The layout of the article follows the traditional path: immediately after these introductory notes, a literature review, limited to the most important, is presented. A presentation of the methodological procedures and an initial profiling of the Database (DB) are the subject of the third topic, which indicates the path followed to obtain the results indicated in the fourth, more detailed section, which also contains the appropriate analyses. Finally, the fifth section contains the overview and concluding remarks.

\section{THEORETICAL CONSIDERATIONS}

This investigation deals with two fields: directly, the scientific field, and additionally, the business field (via the corpus of the MR). As the concept of 'field' is employed, it needs to be defined. In this study, between the six possible interpretations regarding field raised by Machado-da-Silva, Guarido Filho, and Rossoni (2006), it is sufficient to simultaneously accept field as a "set of organizations that share common meanings systems and that interact more frequently with each other than with authors from outside the field, thus constituting a recognized area of institutional life" - following DiMaggio and Powel, according to Machado-da-Silva, Guarido Filho, and Rossoni, (2006, p.162); and as a "set formed of usually integrated and interlinked relationship networks, which emerge as structured and structuring environments [...]", as proposed by Powell, White \& Owen-Smith, and also consistent with Machado-da-Silva, Guarido Filho, and Rossoni (2006, p. 162). Opting for these proposals, no important room is given to, for example, the proposal of Bourdieu (2004) as field being an arena of power and conflict.

Thus, the business field has the Administrator as one of its agents, responsible for the release of the MRs meant for the internal consumption of entities in this field, but borrowed from by Researchers, members of the scientific field, and self-appointed to analyze MRs in order to understand the meanings behind, the production conditions, and the implications of the document.

It is accepted that both the Administrator and the Researcher, seeking that which is in their best interest - almost always involving reputation, prestige, recognition, well-being, and more material rewards - are immersed in their fields, subject to the limitations and facilitations imposed by the corresponding institutional environment, which ultimately directs how 'the game must be played' and what is expected in terms of these agents' conduct (Teixeira, Cappelle, Perdigão, \& Antonialli, 2013, Araújo, Antonialli, Guerrini, \& Oliveira, 2011, Rossoni \& Machado-da-Silva, 2008). However, if the logics, resources, preference between types of reward, and even the understanding of things can be conflicting within a field (Greenwood, Raynard, Kodeihl, Micelotta, \& Lounsbury, 2011), the greater the likelihood is of them being different between fields, and even opposing at times, such as the understanding of knowledge as a public good, in the case of the scientific field, and knowledge as a property right, in that of companies; measured disclosure for companies and total disclosure for the researcher. It seems reasonable, in the dynamic studied in this investigation, to demand transcendence from the Researcher, who should place themselves, at some point, in the position of the Administrator, and not the opposite. This initial point having been established, it seemed appropriate to use the institutional viewpoint to understand the studies regarding MRs, highlighting the coincidence of this also being the base for the majority of MR studies.

\subsection{Institutionalization and Legitimization}

Given the presence of P. Bourdieu in studies in the area, as discussed by Machado-da-Silva, Guarido, Filho, and Rossoni (2006), it is important to quickly acknowledge that, even though Bourdieu is mentioned in the previous section, he was not the reference supporting this paper (assuming that his connection with institutionalization derives from his habitus proposal, which does not play an important role in the analysis). More significant were DiMaggio and Powell $(1991,2004)$ and the interpretations of Machado-da-Silva, Guarido Filho, and Rossoni (2006).

The literature presents different aspects of Institutional Theory. Hall and Taylor (1996) proposed these aspects being fit into three schools: (i) economic or from the rational school, through which, in the search for efficiency, organizations aim to adapt governance structure to institutions and technology; (ii) historical, comparative, which understands institutions as the political legacy of historical struggles, where the success of organizations would depend on coalitions between them; and (iii) sociological or neo-institutionalism, focused on understanding the how, the why, and the consequences of organizational behavior, dealing with organizational fields in the institutional context (Jacometti, Gonçalves, \& Castro, 2014).

Neo-institutionalism has received the attention and corresponding endorsement of a significant number of researchers, accounting for as many as $40 \%$ of submissions to the Organizational Theory section of the annual congress of the Academy of Management in 2012 (Powell \& Bromley, 2013). It is highly interesting to the study of how the environment outside the organization provides it with models for its structuring and for its strategic actions and thus increases the legitimacy of this organization before the world (Powell \& Bromley, 2013). 
For neo-institutionalism theorists, institutions would be systems of symbols, cognitive frameworks, and moral models that provide "patterns of meaning" that guide human action (Nee, 1998). It can be added that some institutional procedures could be considered as cultural practices. These practices would be incorporated into organizations, not only because they increase their abstract efficiency (in terms of means and ends), but in consequence of an acculturation process, imposed by four mechanisms: (1) regulative, via rules, laws, and sanctions; (2) normative, via certification and acceptance; (3) mimetric, through predominance and isomorphism; and (4) cognitive. The regulative mechanism has social control in its informal portions, monitoring, and control. Via the normative mechanism, institutions lead individuals to perform specific roles, internalizing the rules associated with these roles. In the mimetric mechanism, organizations imitate each other, reducing uncertainties (DiMaggio \& Powell, 1991, 2004; DiMaggio, 1995; Scott, 2000). Via the cognitive mechanism, institutions influence behavior in providing frameworks and cognitive models, accepted as crucial for action, facilitating an interpretation of the world and agents' behavior (DiMaggio, 1995).

Through the joint action of these mechanisms, organizations would adopt certain practices because they have a recognized value in the environment in providing useful information; at the same time that they affect identity, self image and the preferences that guide the action of organizational agents - and thus the institutions would be stable over time because they structure their own decisions concerning a possible reform that the individual may seek when subject to institutional models (Hall \& Taylor, 1996).

Legitimization is presented as compensation for the conformity of institutions via mutual acceptance (DiMaggio \& Powell, 1991, 2004; DiMaggio, 1995; Scott, 2000). In this case, the definition from Suchman (1995) is adopted, which is popular in DB texts and defines legitimacy as a perception or generalized assumption that the actions of an entity would be desirable or adequate or appropriate within the existing system and socially constructed from norms, values, beliefs, and definitions - recognizing that companies would need to have legitimacy in the environment in which they operate in order to achieve their goals.

Other legitimacy theorists include Wilmshurst and Frost (2000), O'Donovan (2002), and Lindblom (1994). From them, it would be reasonable to understand the publication of MRs as an opportunity for organizations to demonstrate the congruence of their values (at least in the Administrator's discourse) with their institutional environment in attempting to promote themselves or defend their image and their direction (Stanton, Stanton, \& Pires, 1994). This acceptance is a very common denominator in the studies from the DB.

An interesting suggestion of the role of the institutional environment regarding the content and form of annual reports is contained in the paper from Liberato and $\mathrm{Pa}$ gliarussi (2008), who in studying reports from 4 countries via regression analysis and equality of means tests, con- sidering the different cultural and corporate governance (legal protection and concentration of ownership) dimensions, indicate that the extent of voluntary disclosure of corporate strategies is greater in common law countries (in this case, the United States and United Kingdom) than in civil law countries (Brazil and France). This, in a way, is confirmed by Murcia, dos Santos, Salotti, and Nascimento (2010) in their presenting evidence of research indicating that voluntary disclosure varies in accordance with the country and activity sector.

There would be sufficient evidence indicating that actions are enmeshed in the institutional structures that they themselves produce, reproduce, and transform - with a greater or lesser degree of reflexibility in accordance with the Theory of Structuration from A. Giddens, since the institutional environment would favor the likelihood of adopting a given behavior to the detriment of others (Jacometti, Gonçalves, \& Castro, 2014). However, it is questioned how much real room there would be for Institutional Work (IW), understood as the intentional, individual, or collective social action - physical or mental - of individuals and organizations for, in their organizational field, reconstructing, altering/adapting, or maintaining rules, ownership rights, access to resources, professional identities, systems of meaning, education, and abilities - or even actions aimed to undermine the existing institutions undesired by that agent, who attempts to undo sanctions rules and undermine the moral foundations, beliefs, and values that support such institutions (Lawrence, Suddaby, \& Leca, 2011; Jacometti, Gonçalves, \& Castro, 2014). This discussion is beginning to gain terrain in Brazil and could be an interesting path for MR analysis.

\subsection{Scientific Field and Institutional Environment for Research in Brazil}

In 2013, Brazil had 77,067 professors, spread over 3,486 Master's and Doctorate Programs (Brasil, 2015). This is the largest contingent of the entities taking part in the country's research environment, to which must be added - without being exhaustive - the R\&D departments of private companies, federal and state research institutions (such as Embrapa, Inpe, Fundação Oswaldo Cruz, IPT), research networks (such as the Brazilian Coffee Research and Development Consortium and the Genome Project), promoting and fostering agencies (such as $\mathrm{CNPq}$ and Fapesp), the Ministry of Science, Technology, and Innovation and the equivalent State Secretariats, journals promoting science, research users, and finally, but prominently, the Coordination for the Improvement of Higher Education Personnel (Capes), responsible for evaluating post-graduation stricto sensu. It would be reasonable to consider that this organizational field is simultaneously immersed in Brazilian society and in the general scientific world, the institutions from these origins sharing, for example, the 'jeitinho brasileiro', or 'Brazilian way of doing things', and the 'publish or perish' attitude. However, in addition, it develops its own laws from the scientific field in the country's institutional environment. 
For Silva (2015), the Capes journal evaluation criteria, together with support grants, have structuring power over Post-Graduation Programs, interfering in the strategic conduct of Program coordinators and researchers, led to work in networks (even when unnecessary) due to the valorization of inter-disciplinarity and of inter-institutionality, regarded as values.

Araújo (2008) developed a model based on the Institutional Theory, considering that the formation of collaborative research networks requires researcher investment, in terms of time, attention, and even financial, in order to create and maintain connections. Part of this investment comes in a conscious way (strategic); another, due to habitus; and another still from mere isomorphic imitation (though this results in legitimacy among pears) or from pressure from the institutions present in the network; noting that the conscience investment would only be made because the agents imagine that they will receive compensation higher than the investments made. The compensation would come from different and interconnected sources, in terms of valuable information, legitimacy, physical-emotional well-being, status, prestige, power, and even economic rewards (such as, for example, funding for projects); compensation that would be obtained via the strategic mobilization of resources contained in the network (accessibility to information, to people in power, to prestigious people, to some other resource required by the study, such as laboratories). However, mobilization would depend on the agents' perception of their position and place in the network, the resources available, and the network dynamic itself; reinvestment would depend on the agents' perception of obtained and achievable rewards.

The study of collaborative networks - usually using sociometric analysis of the links established through co-authorship or partnership in projects to trace the structure of the arrangement, discuss its dynamic and reveal the logic and impact of the links - already has a certain tradition in Brazilian academia, including in papers focused on controlling, accounting, and finance (areas that are customarily concerned with the MR) researcher networks, such as the studies from Cruz, Espejo, Costa, and Almeida (2011), Mendes-da-Silva, Onusic, and Giglio (2013), Moraes Júnior, Vasconcelos, and Monte (2014), and Nascimento and Beuren (2011). But, obviously, networks' concerns may also involve other areas of knowledge, such as, for example, the paper from Araújo, Antonialli, Guerrini, and Oliveira (2011) on agricultural science and from Neiva and Corradi (2010) on psychology; even reaching specific issues, such as the paper from Watanabe, Gomes, and Hoffmann (2013), which studied cooperation among groups researching strategy in Brazil.

Based on these papers, it is proposed that researchers, within their networks and immersed in their institutional environments, have two primary targets: funding of their research and publishing the results, which will award them with credentials for their acceptance in the academic community, in this case that of Brazil. With this aim, they follow a less risky model - such as that identified here in the interpretation of MRs - and publish according to what is expected.

\section{METHODOLOGICAL PROCEDURES AND DB CHARACTERIZATION}

This is a documental (articles in journals were the primary source of data) and longitudinal (the articles selected to compose the sample were published from 2000 to mid 2015) study, with a descriptive purpose (in aiming to describe the way in which Brazilian academia deals with the MR), from a predominantly interpretivist viewpoint which made use of, when possible, the triangulation allowed by the use of qualitative (content analysis) and quantitative (statistical, sociometric, and biometric analyses) methods.

While most of the procedures applied in the study follow routes that are well established in biometric studies, it should be noted that the construction of the Synthetic and Generalist Description (SGD) of Brazilian articles that have used the MR, as laid out in detail in section 4.1, is a project with its own properties, inspired solely by the purpose - and not by the technique - of the Collective Subject Discourse from Levebre and Levebre (2003), which is: reconstituting a collective empirical entity, respecting qualitative and quantitative aspects of individual contributions. Any validity intended by SGD, derived from observation of its procedures, is restricted to the sample worked on and its extension beyond these limits gives rise to non quantifiable uncertainties.

\section{1 Constitution and Initial Characterization of the Databank}

The aim of the study was defined as that formed by papers available on the internet and published in Brazilian journals from 2000, including those that made explicit use of the Management Report as an empirical artifact, even when competing with other items, such as, for example, Explanatory Notes, Social Reports, and Environmental Reports. For practical purposes, it is assumed that the quantity (size of the population) of articles that fits into this description is unknown.

By definition, theoretical essays did not take part in the selection, nor papers published in annals and in the form of theses and dissertations. This restriction is a way of avoiding the recurrence of the same study, in the expectation that it would be a natural for the researcher to carry out the work as a conclusion of post-graduation, publishing some results in Congresses, and finally culminating in journal publication.

The starting point for constructing the corpus of analysis was the selection of the first twenty papers obtained from the Google Academic search engine which met the pre-established criteria. The references from these papers offered recommendations for the incorpo- 
ration of the second set of articles and from these for new papers, in a dynamic recognized in sociometry as the snow ball effect. The process was concluded when out of four recommendations; three already composed the Database (DB), which, in the end, included 95 items. This stage was concluded in February of 2015, which marked the end of the period examined.

The result, even though apparently objective, is not statistical: the Google Academic search engine revives papers via its own algorithm which, professedly, offers the results in order of relevance and impact. This, plus the snowball effect, limits the chances of choosing more recent papers and those that do not more emphatically mention the Management Report in their title and in the text. Therefore, an extrapolation of the findings obtained from the sample is subject to unquantifiable uncertainties and imprecision.

The distribution of papers over time favored the period from 2007 to 2012, with an average of twelve papers per year, falling from then onwards, which may, at least in part, be debited to the sample bias. However, the lower average of two papers from 2000 to 2007 appears to be an indication that the Management Report was not very attractive to researchers at that time.

Of the 95 papers selected, only 40 mention the MR in their titles. The rest mention MR among the key wor$\mathrm{ds}$ and/or in the abstract or in the text alone. This practice made recovering the items difficult and may have prevented the participation of studies which would otherwise be present in the DB.

The papers were published in 48 different journals. Of these, 29 served as a vehicle for only one article. In contrast, the journals Revista UnB Contábil/Contabilidade, Gestão e Governança and Revista Universo Contábil, with nine and seven papers, respectively, were the most present journals in the DB. It should be reported that, despite the previous indication, there was no significant preference for journals typically focused on Accounting (52 papers were published in journals from the subarea, compared with 43 divulged in journals with a wider scope). Additionally, using the Qualis classification and score from the Capes Foundation of the Ministry of Education for the Area of Administration, Accounting, and Tourism, 9 papers were found in A2 (80 points each one), 29 in B1 (60), 31 in B2 (50), 22 in B3 (30), 3 in B4 (20), and one was not evaluated, thus giving a total of 4,730 points, averaging 49.8 , equivalent to B2 quality: the articles that worked with the Management Report mostly managed to get published in journals with a good reputation.

\subsection{Theoretical and Methodological \\ Characterization of the Papers Selected}

A quantification of the studies from the DB was carried out in connection with the references presented in their literature review and the qualitative and statistical techniques applied in the development of these papers. Table 1 (divided into 1A, 1B, and $1 \mathrm{C}$ ) presents the result obtained.

Table 1 Literature review and study techniques

\begin{tabular}{|c|c|c|c|}
\hline Table 1A: Literature review & $\mathbf{n}$ & Table 1C: Quantitative technique & $\bar{n}$ \\
\hline Focused on current knowledge & 64 & Scoring and/or descriptive statistic & 55 \\
\hline With greater emphasis on theoretical foundation & 31 & Sophisticated technical statistics & 40 \\
\hline - Theory of voluntary disclosure & 13 & - Regression Analysis & 15 \\
\hline - Theory of legitimacy & 11 & - Correlation Analysis & 9 \\
\hline - Corporate governance & 7 & - Test of Hypotheses & 8 \\
\hline - IMAP 1 Evolutionary stages & 3 & - Cluster Analysis & 4 \\
\hline - Relationship hypothesis & 2 & - Correspondence Analysis & 3 \\
\hline - Political costs hypothesis & 2 & - Process Hierarchy Analytic & 3 \\
\hline - Theory of agency & 2 & - Data Envelopment Analysis & 2 \\
\hline \multirow[t]{2}{*}{ - Ferrarini, Moloney, and Ungureanu Model } & 1 & - Sociometry & 2 \\
\hline & & - Factor Analysis & 2 \\
\hline Table 1B: Qualitative technique & $\mathbf{n}$ & - Principal Components Analysis & 1 \\
\hline Content analysis & 66 & - Association Analysis & 1 \\
\hline Discourse analysis & 4 & - Discriminant Analysis & 1 \\
\hline Narratives analysis & 1 & - Time Series & 1 \\
\hline Semantic analysis & 1 & - Wilcoxon Signed Ranks Test & 1 \\
\hline Comparative analysis & 1 & & \\
\hline Not indicated & 21 & & \\
\hline Not applicable & 2 & & \\
\hline
\end{tabular}

Note. some studies used more than one theory and others more than one statistical technique.

Source: Developed by the authors.

In the studies selected, there was a preference for the presentation of current knowledge - studies from other authors from the same theme of investigation in question - in 64 of the 95 studies. There was greater invest- 
ment in theoretical foundation, notably the contribution from the theory of voluntary disclosure (in 13 studies) and from the theory of legitimacy or legitimization (11 studies).

As expected, the use of the Management Report implied the employment of qualitative techniques for analysis (except in two cases: one essay and one investigation regarding the use of graphics in MRs), with a strong preference for content analysis. Most of the time (55 out of 95 cases), the mathematical treatment came down to counting the occurrences of disclosure, or - when a lot - required the use of basic descriptive statistics, such as average and standard deviation. In 40 cases, however, more sophisticated methods were present, such as regression (15 papers) and correlation (9 papers) analyses and tests of hypotheses, such as the Student t, ANOVA, Kruskall-Wallis, and chi-squared tests (8 papers).

One point should be highlighted: the ontological design of the studies from the DB. With only six exceptions, it is reasonable to conclude that the authors from the $\mathrm{DB}$ aimed to ensure the validity of their work, reinforcing aspects of objectivity, with the expectation that others would arrive at the same conclusions in following the method proposed (frequently, counting disclosures per categories) and working with the same MRs: the inherent subjectivity of qualitative analyses, when mentioned, is treated as a limitation, as discussed in section 4.4.

\subsection{Authorship Characterization of Selected Papers}

A priori, it was decided that the scientific work must be contextualized, both socially and historically: there would be no way of understanding the product - the MR studies - ignoring the factors and production and consumption conditions over time. With this in mind and motivated by observation of the Institutional Theory, substantial investment was made, in this and the next subsection, focusing on authorship characterization of those who are inextricably responsible for the studies and the use of the results from other papers that proceeded them.

Firstly, it is noted that the 95 articles from the BD were of 155 different authorships, with a total of 283 participations. There was therefore an average of 1.8 participations per researcher and 3.3 authors per article. These authors were found to be linked to 47 institutions (almost all universities and schools of higher education, with only three exceptions) at the period of the respective articles, which implies an average of 6 participations per institution.

However, the average reveals little of the distribution found, in that Researcher 55, the most frequent, appears in 28 articles (thus, in $30 \%$ of the papers, earning them 1,410 points according to Capes - this in only eight years since their first article in 2006, which implies 176 points per year), while 116 authors ( $75 \%$ of the total) had only one participation. Similarly, with regards to the institutions: 24 of the 47 entities appear only once, while the University of São Paulo (USP), the Federal University of Santa Catarina (UFSC), and the Regional University of Blumenau (FURB) had 20, 39, and 104 participations, respectively, through their researchers. These distributions, of many with little and few with a lot, are in line with other scientometric papers, which offers some comfort regarding the representativeness of the sample.

For convenience, the current titles of the researchers from the $\mathrm{BD}$ (and not those from when their articles were published) were studied using the respective Lattes system curricula of 134 authors - thus, $86 \%$ of the sample. Of these, 70 are doctors (two with $1 \mathrm{~A}$ productivity grants from CNPq, one of them, Researcher 55, being central to the authorship network; and 13 with level 2 grants, indications of competency in research), while 56 have the highest title in master's. Most of the authors obtained their master's and/or doctorate titles in the subarea of Accounting (or a variant, for example Accounting Science); 96 of the 126 have these title levels. As well as Accounting, Management also stands out, with 25 masters and/or doctors, and Production Engineering, with 16. It is also noted that USP awarded most of the titles: 57 of the 194 master's and doctorate titles. Following that, UFSC appears with 32 and FURB with 19 titles.

Joint-authorship was found to be a rule (only 6 papers had a single author, while the rule was 3 authors per article). However, the association of two or more entities was limited to 36 of the 95 papers, indicating the prevalence of intra-institutional work and thus some restriction on greater circulation of knowledge.

\subsection{Sociometric Characterization of the Arrangement of Researchers}

The 95 papers, with their 155 authors, involved 273 different didactic links, configuring a fragmented arrangement of 20 components, only one of them large, with a diameter of 8 , the result of the connection of 93 nodes. It involves a low density (of 0.023 ) and low connectivity (of 0.368 ) arrangement and an average degree (= average number of partners) of 3.57 - noting the disparity, again of node 55, with 22 different partners.

Figure 1 represents the arrangement, where the node color serves to identify its entity, thus: yellow = Regional University of Blumenau (FURB); green = Federal University of Santa Catarina (UFSC); red = University of São Paulo (USP); dark blue = Federal University of Ceará (UFC); black = Federal University of Minas Gerais (UFMG); light blue = University of Brasilia $(\mathrm{UnB})$; pink $=$ Federal University of Paraná (UFPR), and finally, white $=$ other entities.

Analyzing the largest component, it is verified that its nucleus is composed of professors, doctorate and master's students, and former students of FURB, found to be connected with each other, with one exception (Researcher 106, far from the largest component, in the lower left corner of Figure 1). To this nucleus and through some nodes acting as bridges (the case of Researchers 12, 55, and 99, for example), 
clusters of researchers from UFSC, UFC, and UFPR are linked, and in these are connected clusters of researchers from USP and UFMG. In the arrangement, the role of node 129 should also be noted, which is important in linking FURB to its entity (UFPR) and to UFMG. The researchers from UnB do not form part of the largest component, but are connected to each other in a separate component.

As already observed, the researchers tended to seek partners in their institution, with some exceptions (Researchers 12, 55, 99, and 129 stand out), thus acting to avoid the constitution of more structural gaps, as is also the role of Researchers 41, 141, 126, and 117, who together with 55 and 129 have the lowest levels of aggregate constraint. However, it is Researcher 55 who stands out the most: with the largest number of partners (43 direct links with 22 different nodes) and who is most central in the arrangement.
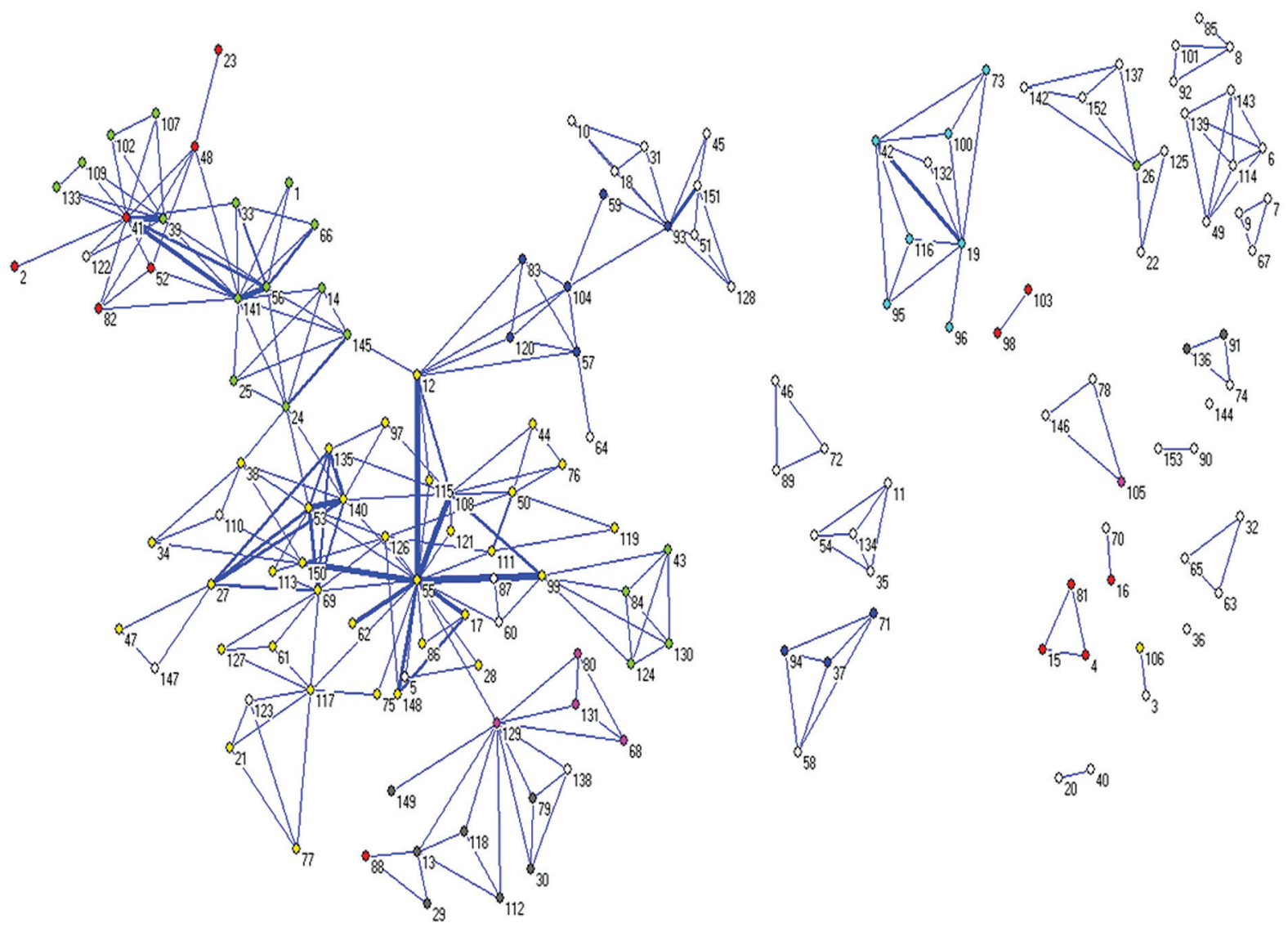

Figure 1 Sociometric network arising from the $D B$ Note. Nodes = researcher; color of node $=$ his/her organization. Source: Data from the study.

An important feature, obtained from the intersection of authorship with the MR set examined in each paper, is the maximization of 'efficiency' in terms of research: 9 situations were found involving a total of 25 of the 95 papers from the DB in which exactly the same MR set was used more than once; some of them, using the same analysis techniques, in papers that could be taken as complementary, yielding publications in other journals. This phenomenon could be associated with the 'proliferation of studies', which was discussed in Castiel and Sanz-Valero (2007) in the public health field of science, explainable by the imperative to publish and accumulate Capes points. This contributed, in some measure and in an artificial (and, it could be said, spurious) way, to the thickening of certain linking lines in the sociogram in Figure 1.

\subsection{Implications for the Study}

Enough indications were gathered to determine the property of the MR as a source of data in studies collectively conducted by qualified researchers who turned them into articles publishable in journals with good reputations. As a natural result of subarea expertise and also confirmed by analysis of the DB, the prevalence of the Accounting viewpoint in the MR analyses is again acknowledged, a priori, with implications that warrant reflection. Additionally, the DB is not depersonalized: some researchers are in structural positions, which gives them significantly wide powers of operation.

Finally, a cohesive and central group formed by Researcher 55 and fellow professors, students, and former students from the FURB Post Graduate Program 
in Accounting became expert in the MR and may have been used as a reference for the researchers from the largest component, shaping the papers to the study strategies of the nucleus.

\section{RESULTS AND ANALYSIS}

\subsection{Design of the Studies from the DB}

The first approach in the corpus of this investigation per se was centered exclusively on title and key words. This resulted in 497 noun phrases (ignoring articles and prepositions, for example); of these, 190 were distinct. The terms were grouped considering their meaning into six groups plus the 'Others' group, which had terms taken without close association (111 of the 497 occurrences). The six other groups were called: 'Disclosure', with 89 occurrences; 'Type of disclosure', with 88; 'Framing of companies analyzed', with 84 occurrences; 'Source or origin of data', with 63; 'Methods for analysis', with 34; and 'Reference standard', with 27 occurrences.

In the next step, with the aim of revealing the theoretical support for the studies, the set of terms associated in a relevant way with the 'theor' (from theory and theoretical) root was taken in the articles from the DB.

The two findings were combined and gave rise to a Synthetic and Generalist Description (SGD) of the papers, with the following formulation:

"Study of the disclosure ${ }^{1}$, via the use of one and/or more methods of analysis ${ }^{2}$, of data source ${ }^{\underline{3}}$ from authorship from a company or companies from a particular or general sector of the economy 4 compared to $\underline{\text { reference standard }(s)})^{5}$; correlated or not with another factor $^{6}$, from the viewpoint of some theory or theo$\underline{\text { ries }}^{7}$, in the period....".

Fictitiously, the SGD would cover in its scope, for example, the description of a "study of [environmental] disclosure, via [content analysis] of [Management Report and Explanatory Notes], from [publicly-traded Brazilian companies from potentially polluting sectors] compared to [American disclosure practices], correlated with [the financial performance of those Brazilian companies], from the viewpoint of [the theory of voluntary disclosure], in the period [from 2006 to 2008]". It is proposed that this standard (SGD), constructed over time, could be taken as an institutional display from Brazilian academia of how to conduct studies on voluntary disclosure.

The elements from the superscript categories 1 to 7 of the SGD, mapped in the corpus, were found in accordance with Table 2.

\section{Table 2}

\begin{tabular}{cl}
\hline ITEM & ELEMENTS \\
\hline 1 & $\begin{array}{l}\text { Disclosure + (its type: environmental; of carbon credits; of environmental investments; of environmental costs; of environmental } \\
\text { liabilities; of environmental risk management; of (general) risk management; of categories of risks; and others), with environmental } \\
\text { disclosure standing out in terms of frequency,. }\end{array}$ \\
\hline 2 & As presented in Tables 1B and 1C \\
\hline 3 & $\begin{array}{l}\text { Social report; Standardized Financial Statements (SFS); Explanatory Notes (EN); other reports; and, naturally, having been taken as } \\
\text { selection criterion for the DB: the Management Report, present in all cases. }\end{array}$ \\
\hline 4 & $\begin{array}{l}\text { Industrial companies: Eletronuclear; Petrobras; from the food and beverages sector; companies from Ceará with American Depository } \\
\text { listed in Bovespa Levels of Corporate Governance (NCGB); best to work at, those potentially polluting, and others. }\end{array}$ \\
\hline 5 & $\begin{array}{l}\text { CVM 15/87; Evolutionary stages of the International Management Accounting Practice (IMAP); USA; Europe; organizational legiti- } \\
\text { mate governance; Ethos Institute proposal and others - with emphasis on CVM 15/87 and NBC T 15. }\end{array}$ \\
\hline 7 & Financial performance; reputation; market value; share volatility; social performance; capital structure; and cost of debt. \\
\hline
\end{tabular}

It was found that the proposed SGD, well adjusted to the positive theory of accounting, encompasses 82 of the 95 studies from the DB, not necessarily implying that these use all of the SGD elements.

The 13 studies not met by the SGD tend to have a more interpretivist orientation, sometimes using discourse analysis (instead of counting sentences per category, typical of key content analysis), without being concerned with disclosure, but rather with the terms themselves, potentially revealing the figure of the
MR author, such as, for example, Grande and Beuren (2011):

The study aims to verify whether changes in management accounting practices can be identified in the Management Reports of family companies via the use of Critical Discourse Analysis. The research methodology is characterized as exploratory, with a predominantly qualitative approach, using Critical Discourse Analysis (...) It is concluded that, (...), changes were 
identified in the management accounting practices of the companies studied. However, there is no guarantee that the MR effectively represents management discourse and subjective analysis may reveal inaccuracies.

A significant portion of the studies from the DB considered a cross section appropriate (46 of the $95 \mathrm{ca}-$ ses). When a longitudinal section is chosen, it was of two years in 6 papers; three years in 12 papers; four years in four papers: five years in 10 papers; seven years in two papers; nine years in two papers; 10 years in nine papers; and 13 years in one paper. Considering the different cut-off periods and the juxtaposition of the years resulted in a representation as in Figure 2 (of year and frequency), providing evidence of a greater presence of the years 2006 (42 studies); 2007 (36 studies); and 2008 (29 studies) in the DB and only one in the two extremities.

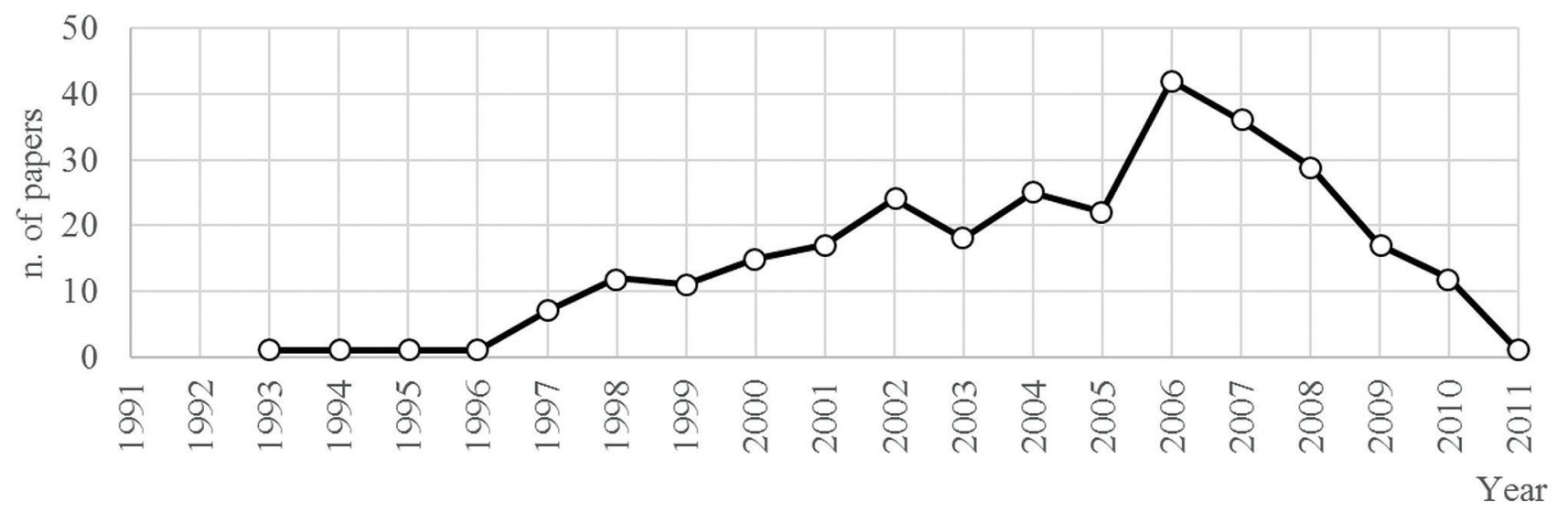

Figure $2 \quad$ Number of papers in the DB per year

Note. Area under the curve is greater than 95 due to longitudinal sections.

Source: Data from the study.

With regards to the number of companies and from this the number of MRs examined (that declared or obtained by multiplying the number of companies by the number of years from the chosen cut-off), a variation from 1 to 448 and from 4 to 2,639 is found, respectively - in such an unequal distribution that it is better represented in logarithmic scale, as in Table 3, where $\mathrm{f}$ equals the frequency of each class, indicated between the columns 'From' and 'To'.

Distribution of number of companies and number of MRs examined in the studies

\begin{tabular}{|c|c|c|c|c|c|}
\hline From & To & $\begin{array}{l}\text { From } \\
(\log )\end{array}$ & $\begin{array}{c}\text { To } \\
(\log )\end{array}$ & $\begin{array}{c}f \\
\text { Companies }\end{array}$ & $\begin{array}{c}f \\
\text { MRs }\end{array}$ \\
\hline 0 & 3 & 0.00 & 0.50 & 3 & 1 \\
\hline 3 & 10 & 0.50 & 1.00 & 13 & 6 \\
\hline 10 & 32 & 1.00 & 1.50 & 39 & 26 \\
\hline 32 & 100 & 1.50 & 2.00 & 19 & 30 \\
\hline 100 & 316 & 2.00 & 2.50 & 16 & 20 \\
\hline 316 & 1,000 & 2.50 & 3.00 & 2 & 8 \\
\hline 1,000 & 3,162 & 3.00 & 3.50 & 0 & 1 \\
\hline 3,162 & 10,000 & 3.50 & 4.00 & 0 & 0 \\
\hline
\end{tabular}

Note. The total is lower than 95 due to lack of indication.

Source: Data from the study.

According to Table 3, the greatest frequency was from studies that dealt with 10 to 32 companies, studying 32 to 100 MRs. The variety presented in Table 3 introduces a disturbing element into the evaluation of studies from the DB: that of how to deal with the reliability of results if for some 10 MRs were sufficient, when others needed to study 1,000 . It is evident that the answer lies in the propo- sed goal and in the strategy for resolving the problem, but and if the findings were not consistent? In the quantitative meta-analysis, the adjustment is made considering the sample size and the $\mathrm{p}$-value, which should not be available in papers that did not carry out random sampling, as in the DB.

Taken together with the possibilities offered by the 
SGD, the number of companies and the cut-off period, there is quite a substantial range of research opportunities, favoring the strategic researcher behavior referred to previously: he/she may feel 'tempted' to, for example, maintain the MR set and vary the type of disclosure, or maintain the type of disclosure and the MR set and vary the factor to be correlated, or even opt for another cut-off period, merely updating the research; he /she may also, ceteris paribus, use different criteria to create the list of categories for content analysis, implying different levels for the same type of disclosure, depending on the preferred theoretical viewpoint. There are so many possibilities that the designs of the studies from the DB would not happen to be identical: always something different, which prevents comparing their results.

To conclude, it is acceptable to stress the almost inevitable methodological bias of accountants, authors of the studies in the DB, perceived in converting/reducing a text (the MR) into a number (in this case, the 'level of disclosure') ignoring other considerations of a more interpretivist nature.

\subsection{Reasons for Using the Management Report}

The studies in the DB exhibit, explicitly or implicitly, one or more elements from the set listed below in order to warrant the use of MRs as a source of data.

Primarily, MRs would be relevant, since they perform the role of offering, among other features, information not liable to be disclosed in standardized financial statements, contributing to reducing information asymmetry, which would be desirable for a better working market. As MRs are compulsory for publicly-traded companies (while other narrative reports are optional), most Brazilian stu- dies would use them to quantify disclosure, allowing for comparison of results.

MRs would have a wide range of legitimate parties interested in the information in them, just as the parts of the SFS. Additionally, they are presented together with the SFSs, which would communicate that the MRs hope to offer: a lack of bias, veracity, transparency, ethics, timeliness, relevance, understandability, reliability, comparability, and materiality - which would, in turn, allow for better quality decision making on the part of those related to the entity.

Moreover, because it is less technical, less structured, more flexible, more descriptive (narrative) and not governed by the general principles of accounting as SFSs are, MRs can offer greater communicative quality, be clearer, and facilitate the understanding of a greater number of users, including laymen. Additionally, they would serve as a channel for voluntary disclosure of that which is considered by the company as important, displaying the discretionary power of the Administrator. As a result, they would help to sway the perceptions of interested parties, serving as an instrument for the legitimacy of the entity. In addition, even though this has not been mentioned in the studies in the DB, MRs are more accessible, possibly even the more outlying ones, made available by specialized media, Bovespa, and companies themselves.

\subsection{Findings of the Studies from the DB}

324 segments indicative of summaries of results, conclusions and contributions were gathered. These segments were grouped by topic, into eight categories. Table 4 presents the category, the respective frequency in brackets, and some illustrative examples from the category.

Table 4

Findings of studies from the $D B$

CATEGORY EXEMPLIFICATION

The study showed an evolution that advances towards an improvement in the level of environmental responsibility.

Tendencies (24) It is concluded that the tendency in environmental and social terms shown was to maintain the quality of transparency information constant (...).

The results reveal that, in general, the companies studied meet the items recommended by the CVM Parecer de Orientação guide-

line n. $15 / 87$

The vast majority of companies show only environmental assets, failing to inform their environmental liabilities.

Ex ante connection There is not sufficient evidence to claim that, the larger the independent auditing firm contracted by the publicly-traded company

is, the better disclosure will be.

(78) Unfavorable financial performance is related to high degrees of optimism.

Ex post connection (...) both positive and negative environmental disclosure does not influence the cost of debt.

(19) Indications of optimistic bias (in the MR) do not influence share prices.

Connection of ano- There is a relationship between the environmental information presented in a declarative way with good news released in the ther nature (18) management report

Pessimistic reports center their attention on the economic climate.

Agent interference There appears to be a relationship between changes of president and changes of disclosure strategies in the annual reports released (10) $\quad$ over time.

Challenges to inter- The fluctuation between the permanence or not of certain terms may be related to the environmental and/or social programs Challenges to inter- undertaken by the companies, however discontinued over time, or simply due to the fact that the company has ceased to disclose pretation (5) certain terms

Need to standardize Disclosure is essential for strengthening the capital market, also being a possible alarm for orientating and regulatory bodies regar(55) ding the need to reformulate the rules related to the issue.

Note. $(n)=$ number of occurrences

Source: Data from the study. 
It is interesting to note that some conclusions appear contradictory, depending on the companies, period, and method chosen. Additionally, a third of the conclusions refer to a framework that no longer exists (but which has historical importance and can be updated).

However, taken in conjunction, the MR that emerges in Table 4 is an incomplete document (it would not be able to meet social, environmental, risk management, innovation and other disclosure needs), biased, subjective (subject to Administrator discretion, motivated by his/her own interests); at the same time, it is conditioned by internal (company size, its economic-financial performance, its capital structure, and the quality of its governance) and external (operating sector, incidence of regulatory power) elements, deprived of better quality monetary information.
Given the current stage and positive, but insufficient, path of MR improvement, the alternative would be compulsory harmonization promoted by the regulatory body, bringing the document closer, as much as possible, to an accounting ideal.

\subsection{Limitations Indicated in the Studies from the DB}

106 indications of study limitations were found in 48 of the 95 studies - implying that 47 papers did not explain the respective limitations, a mismatch with the reasonable conclusion that any study would have its own. The indications were listed and semantically connected with each other and then grouped into 9 categories, as in Table 5, which includes an explanatory sample from the group, by way of example.

Table 5

Limitations indicated in the studies

\begin{tabular}{|c|c|}
\hline CATEGORY & EXEMPLIFICATION \\
\hline $\begin{array}{l}\text { Impossible to generalize } \\
\text { (39) }\end{array}$ & $\begin{array}{l}\text { Only the companies listed in the theoretical portfolio from the BM\&FBOVESPA Index were analyzed, involving a non proba- } \\
\text { bilistic sample and its results must not be generalized for other companies or for the same companies in other periods. }\end{array}$ \\
\hline $\begin{array}{l}\text { Subjectivity of qualitative } \\
\text { analysis(18) }\end{array}$ & $\begin{array}{l}\text { The limitation of this study involves the subjectivity present in the content analysis, because the implicit ideas related to the } \\
\text { information analyzed were influenced by personal interpretations and decoding on the part of the researchers. }\end{array}$ \\
\hline MR exclusivity (13) & $\begin{array}{l}\text { The main limitation of this study derives from the fact that the study is only based on company management reports, since } \\
\text { there are other means of disclosing company actions along these lines. }\end{array}$ \\
\hline $\begin{array}{l}\text { Discretionary power of } \\
\text { companies (5) }\end{array}$ & $\begin{array}{l}\text { After all, many companies may have the correct environmental position and not divulge this information. On the other hand, } \\
\text { other companies could adopt an inappropriate position regarding the environment and divulge only good information since } \\
\text { they are not obliged to make this disclosure. }\end{array}$ \\
\hline $\begin{array}{l}\text { Lack of MR standardiza- } \\
\text { tion (3) }\end{array}$ & $\begin{array}{l}\text { (...) one study limitation is due to the Management Report not having a specific standard, which makes comparing this report } \\
\text { between companies difficult. }\end{array}$ \\
\hline Study focus (3) & (...) the study only addresses information related to the environment. \\
\hline Others (2) & (...) the limitations are due to the sparse theoretical framework that exists with regards to the management report. \\
\hline
\end{tabular}

Table 5 appears to indicate that the initial liability of MRs in light of the study limitations would be having their content subject to the Company's discretion (of its Administrator), which may choose what and how to offer voluntary information, which in turn is easily prone to produce insufficient (incomplete) MRs and their lack of standardization.

Nevertheless, a closer look captures how much the MR can add. Being a narrative element, it implied qualitative analysis - whether of content or of discourse. From this, researcher subjectivity implications are noted, not only in the analysis process, but also from the initial choice of one or more theoretical frameworks (for example, corporate governance) or any other mechanism (for example, CVM recommendation 15/1987), which provides the analysis categories and serves as a lens for them.

Not sufficient, the most frequent restriction (it being (impossible to generalize') is related to the intentional and non-probabilistic sampling, associated with the complexity of the qualitative analysis, laborious when trying to reduce the terms to a table of frequency.

\subsection{Future Papers Suggested in the Studies}

132 proposals for future papers were listed in 65 of the 95 studies. In the same way as the previous section, the suggestions were semantically connected with each other, resulting in them fitting into 11 groups which, in turn, could be adjusted into two larger categories and a third ('Others', with proposals unable to be fitted into the larger categories), in accordance with the ultimate, even if implicit proposal, clarified by interpretation of the suggestion. The larger categories revealed by the interpretation of the proposals were:

A - To test or widen the validity of the findings, with 89 suggestions, distributed into: A1 - Comparison with other companies, groups of companies, sectors or region (42 sug- 
gestions); A2 - Adoption of another cut-off period (14 suggestions); A3 - Use of an alternative data source, other than the MR (10); A4 - Application of alternative theories to that employed in the paper (10); A5 - Widening of the sample (6); A6 - Adoption of another analytical model (4); and finally, A7 - Change of focus (with the remaining 3 category suggestions).

B - To study relationships, including those of cause-effect, with 38 suggestions, distributed into 3 groups: B1 - MR production conditions (28 suggestions); B2 - Impact of the MR (7); and B3 - Other relationships between variables associated with the MR (3).

With regards to the first category ('test or widen the validity of the findings'), it would be reasonable to indicate that there is some coherence among the study limitations, the proposals for new papers, and the predominantly descriptive goal of the studies (mapping the frequency of occurrence of certain elements suggested by the literature in the MRs), since having to choose an intentional and time specific sample, any generalization of the description found would be taken as inappropriate, which would require more tests, even of non-random samples as well, 'consolidating' or refuting the original study conclusion. However, this would require all the new studies to use the same metric as the first study, not very likely in light of so many viewpoints liable to being activated, unless these new studies continue under the orientation of the original researchers - which results in a discussion of subjectivity, also indicated as being a limitation.

The other category ('study relationships, including those of cause-effect') includes the proposals for investigating the action of certain variables or features (for example, sector regulation, size, location, and shareholder composition of the company) which act in the decision to disclose (or omit) and how to disclose; as well as testing the influence of the level of disclosure over, for example, share volatility. Regardless of how interesting this last proposal is, it has not attracted much attention from academia, perhaps due to the difficulty, or even impossibility, of keeping the other variables constant, together with the risk of having the study contested by the potential incidence of some 'omitted variable' regarding the relationship found.

\section{CONCLUSION}

If the concept is accepted of institution being that more or less stable element of social life that affects the behavior and beliefs of individuals and collective actors, providing them with templates for action, cognition and emotion which, when implemented, reduce the risks associated with some type of cost (Lawrence, Suddabu, \& Leca, 2011), it would be reasonable to accept the SGD referred to in section 4.1 as an institutional display; follow the model, consolidated at least fifteen years ago, and there will be less chance of having your paper, the fruit of hours of work, being rejected by the scientific field - ignore it and you will suffer from sanctions. Now, this standard did not arise decontextualized in time and space; there is little risk in affirming that it arises from a diligent, deliberate effort or is the fruit of more fortuitous reproduction of accounting professors associated with FURB at the time of production.

Moreover, it can also be claimed that the evidence presented indicates roughly that management-accounting research in Brazil (or more suitably the dominant group of researchers identified in this investigation) has embraced the Management Report, with reservations, since the document appears:

- Biased: the Administrator tends to value good news, attributing it to his/her competence, and to reserve little room (or none, if possible) for bad news, attributing it to external factors.

- Incomplete: it does not address all the elements for evaluating the quality of management regarding environmental, social, risk-related and strategic aspects.

- Questionable, if not suspicious: it allows margin for the false positive (it is mentioned, but does not exist) and the false negative (it is not mentioned, but exists), given that it is not even audited.

- Unclear: it does not use precise terms, distancing itself from precise quantification.

- Laborious and liable to subjectivity, given that it is narrative, which implies a qualitative analysis, with the particular characteristics of this, and the use of non probability sampling in practice.

- Uncertain, since it results from agency mechanisms.

- Useful, in the absence of another; comprehensive, and retrievable over time.

Because of this, the results of studies derived from the MR cannot be generalized and the variables studied, when found with statistical significance (which is arguable, since they are derived from samples for convenience), have a low explanatory power due to the practicing of discretionary power on the part of the Administrator.

A pattern was found; most of the papers adopted the model common to the group of researchers centered on the FURB team, practicing since 2005, which favors the accounting viewpoint: the MR narrative is converted into a level of disclosure and the connection of this variable to some conditioning factor or effect is tested. Observation of this pattern was possible via the construction of the SGD. This contribution is perhaps also a study differentiator (and also, admittedly, a risk). While the majority of bibliometric papers are limited to treating the data analytically, the effort to derive an overview from this was crucial in the opinion of the authors of this study, in the uncovering of the underlying pattern in the material analyzed.

It would be reasonable to note that some of MR researchers' criticisms must be relativized. They make them from an academic point of view (influenced by the institutional 
standards of the Brazilian scientific field), without the authors putting themselves in the place of the potential priority recipients (who belong to the business field). If any doubt remains regarding who they are among those indicated by the CVM, it is not likely that the Administrator considers, even marginally, in the elaboration of his/her MR, the demands of a closed group of researchers, heard by the regulatory bodies. Apparently, the authors in the DB highlight the fact that they are using interpretivist lenses from the scientific field in a document that belongs to the business field, in which a good MR is that which provokes positive reactions (if possible, reflected in a rise in share price), even if it is academically incomplete or biased.

On the other hand, there would be the possibility of extracting new understandings based on MRs. This alternative has already appeared periodically and may warrant more attention, perhaps from another group of researchers, who are closer to the theory of organizations.

If it is acceptable, as defended in the majority of the papers in the $\mathrm{DB}$, that Administrators aim to legitimize their companies, incorporating, at least in discourse, the use of contemporary management practices, it is no less acceptable that such practices are institutionalized also through Administrator discourse (and by other mechanisms), in a dualistic (legitimacy and institutionalization) path over time.

It would be interesting to discover, for example, how 'pollution control' and an 'increase in efficiency' was converted into 'environmental management', from there into 'sustainable development' and resulted in 'sustainability' and 'eco-efficiency', two fashionable terms, and from where it will go from there. In more general terms, how organizations have accepted values or reacted to the pressures of so- ciety, turning them into discursive resources - interesting, even and/or primarily if not applied.

Moreover, if it is possible to find the current discourse of some managers via interviews (after overcoming substantial obstacles), it is postulated that the MR would be the only capable, wide, historic, available, and inexpensive source for investigating the institutionalization of organizational practices - very similar to what is done in academia when the concern is the institutionalization of the same practices (and also theories and methods), when instead of the MR, the sources are scientific texts themselves. Based on this, the proposed study would result in theory and not in descriptive generalizations - showing the duality set out in evidence to be valid.

Additionally, a question would remain open: would MRs be suitable documents for tracing some indication of Institutional Work (IW), understood as an intentional action for changing the institutional environment in the organizational field? Hypothetically, there is the challenge here, in not finding such indications, of showing whether this is due to omission in the MR or the inexistence of IW. In any event, another contribution to management science would remain.

In the end, there is a caveat. A meta-interpretation may be taken as reductionist and unable to maintain the integrity of original papers, each one with their nuances. The criticism is valid, but would be more pertinent when attempting to produce a compilation of original papers (Walsh \& Downe, 2005). This was not the intention here, given that the aim was to supply an interpretation of what stands out in the texts placed under analysis, contributing to the understanding of how academia works and could work with the MR. 


\section{References}

Araújo, U. P. (2008). Relação agência e estrutura em redes colaborativas (doctorate thesis in management). Lavras: Ufla.

Araújo, U. P., Antonialli, L. M., Guerrini, F. M. \& Oliveira, R. F. de (2011). A percepção e as estrạtégias de ação do pesquisador de café em sua rede colaborativa. Revista de Administração Contemporânea, 15(4), 670-688.

Bourdieu; P. (2004). Os usos sociais da ciência: por uma sociologia clínica do campo científico. São Paulo: UNESP.

Brasil (1976). Lei no 6.404, de 15 dezembro de 1976. Diário Oficial [da] República Federativa do Brasil, Poder Executivo, Brasília, DF, 17 dez. 1976. Suplemento, 1.

Brasil (2015). Indicadores selecionados de ciência, tecnologia e inovação Brasil 2015. Brasília: Ministério da Ciência, Tecnologia e Inovação

Castiel, L. D. \& Sanz-Valero, J. (2007) Entre fetichismo e sobrevivência o artigo científico é uma mercadoria acadêmica? Caderno de Saúde Pública, 23(12), 3041-3050.

Comissão de Valores Mobiliários - CVM (1987): Parecer de orientação CVM no 15. Diário Oficial [da] República Federativa do Brasil, Poder Executivo, Brasília, DF, 08 jan.

Cruz, A. P. C. do, Espejo, M, M. dos S. B, Costa, F. \& Almeida, L. B. Perfil das redes de cooperação científica. Revista Contabilidade ¿ Finanças, 22(55), 64-87.

DiMaggio, P. J. (1995). Culture and economy. In: Smelser, N. \& Swedberg, R. The handbook of economic sociology. New Jersey: Princeton University, 1995

DiMaggio, P. J. \& Powell, W.W. (1991). The new institutionalism in organizational analysis. Chicago: University of Chicago, 1991.

DiMaggio, P.J. \& Powell, W.W. (2004). The iron cage revisited. In: Dobbin, F. (Ed.). The new economic sociology. Princeton: Princeton University, 111-134.

Grande, J. F. \& Beuren, I. M. (2011) Mudanças de práticas de contabilidade gerencial identifi-cadas nos RA de empresas familiares. Contabilidade, Gestão e Governança, 14(3), 18-33.

Greenwood, R., Raynard, M., Kodeih, F., Micelotta, E. R. \& Lounsbury, M. (2011). Institutional complexity and organizational responses. The Academy of Management Annals, 5(1), 317-371.

Hall, P. A. \& Taylor, R. C. R. (1996). Political science and the three new institutionalisms. Political Studies, 44(5), 936-957.

Jacometti, M., Gonçalves, S. A. \& Castro, M. de. (2014). Institutional work e conhecimento em redes interorganizacionais. Revista de Administração Mackenzie, 15(6), edição especial, 17-47.

Kos, S. R., Espejo, M. M. dos S. B. \& Raifur, L. (2014). O conteúdo informacional do Relatório da Administração e o desempenho das empresas brasileiras do Ibovespa. Revista Universo Contábil, 10 (2), 43-62.

Lawrence, T., Suddaby, R. \& Leca, B. (2011) Institutional work: refocusing institutional studies of organization. Journal of Management Inquiry, $20(10,52-58$.

Lefevre, F. \& Lefevre, A. M. C. (2003). O discurso do sujeito coletivo: um novo enfoque em pesquisa qualitativa. Caxias do Sul: Educs.

Liberato, G. B. \& Pagliarussi (2008). Disclosure de estratégia em relatórios anuais. Fucape Working Papers, 3, 28p

Lindblom, C. K. (1994). The implications of organizational legitimacy for corporate social performance and disclosure. Anais Critical Perspectives on Accounting Conference. New York.
Machado-da-Silva, C.L., Guarido Filho, E. R. \& Rossoni, L. (2006) Campos organizacionais: seis diferentes leituras e a perspectiva de estruturação. Revista de Administração Contemporânea, Edição Especial, 159-196.

Moraes Júnior, V. F. de, Vasconcelos, A. F. \& Monte, P. A. do. (2014). Perfil dos trabalhos publicados de 2004 a 2010 na área educação e pesquisa do congresso USP de controladoriạ e contabilidade. Revista Ambiente Contábil, 6(2), 36-54.

Murcia, F. D-R., dos Santos, A., Salotti, B. M. \& Nascimento, A. (2010) Mapeamento da pesquisa sobre disclosure ambiental no cenário internacional. ConTexto, 10(17), 7-18

Nascimento, S. do \& Beuren, I. M. Redes sociais na produção científica dos programas de pós-graduação de ciências contábeis. Revista de Administração Contemporânea, 15(1), 47-66.

Nee, V. (1998). Source of new institutionalism. In: Briton, M., Nee, V. (Ed.). The new institutionalism in sociology. New York: Russell Sage Foundation, 1-17.

Neiva, E. R. \& Corradi, A. (2010). A. A psicologia organizacional e do trabalho no Brasil. Revista Psicologia: Organizações e Trabalho, 10(2), 67-84.

Q'Donovan, G. (2002). Environmental disclosures in annual report. Accounting, Auditing \& Accountability Journal, 15(3), 344-371.

Powell, W. W \& Bromley, P. (2013): New institutionalism in the analysis of complex organizations. International Encyclopedia of Social and Behavioral Sciences, $2^{\text {nd }}$ Edition, $13 \mathrm{p}$

Rossoní, L. \& Machado-da-Silva, C. L. (2008). Análise institucional da construção do conhecimento científico em mundos pequenos. Faces Journal, 7(1), 25-41.

Scott, W. R (2000). Institutions and organization. 2.ed. London: Sage, 2000

Silva, R. C. F. da (2015). Programa de 'pós-graduação em administração da Ufla (master's in management dissertation). Lavras: Universidade Federal de Lavras

Stanton, P., Stanton, J. \& Pires, G. (2004). Impression of an annual report an experimental study. Corporate Communications: an International Journal, 9(1), 57-69.

Suchman, M. C. (1995) Managing legitimacy: strategic and institutional approaches. Academy of Management Journal, 20(3), 571-610.

Teixeira, J. C., Cappelle, M. C. A., Perdigão, D. A. \& Antonialli, L. M. (2013). O campo científico na percepção de docentes de uma universidade: Revista GUAL, 6(3), 86-110.

Walsh, D. \& Downe, S. (2005). Meta-synthesis method for qualitative research: a literature review. Methodological Issues in Nursing Research, 50(2), 204-211.

Watanabe, E. A., Gomes, A. O. \& Hoffmann (2013). Cooperação entre grupos de pesquisa em estratégia no Brasil. Revista Ibero-Americana de Estratégia, 12(1), 84-106.

Weed, M. (2005). "Meta Interpretation": a method for the interpretive synthesis of qualitative research. Forum: Qualitative Social Research, 6(1), art. 27.

Wilmshurst, T.D. \& Frost, G.R. (2000). Corporate environmental reporting a test of legitimacy theory. Accounting Auditing and Accountability Journal, 13(1), 10-26, 2000.

Wood, P. Meta-analysis. In: Breakwell, G: M.; Hammond, S. \& Fife-Schaw (Eds.) (2000). Research methods in psychology. London: Sage, 414-425.

\section{Correspondence Address:}

\section{Uajará Pessoa Araújo}

Centro Federal de Educação Tecnológica de Minas Gerais, Campus II, Departamento de Ciências Sociais Aplicadas

Avenida Amazonas, 7675 - CEP: 30.421-169

Nova Gameleira - Belo Horizonte - MC

Email: uajara@dcsa.cefetmg.br 